\title{
Em busca da zona fronteiriça: o futuro do pensamento de Tillich diante da (futura) configuração da humanidade
}

\author{
Wanderson Salvador Francisco de Andrade Campos*
}

\section{RESUMO}

O presente texto evidencia alguns momentos da vida de Paul Tillich, entendidos como fronteiras, o relacionamento familiar, o choque ao mudar do campo para a cidade e a experiência como um imigrante, ao mudar de país. Esses eventos, que o afetaram na infância, na adolescência e o acompanharam durante toda sua existência, o ajudaram a elaborar seu pensamento. Ao destacar esses pontos da vida de Tillich, o presente texto buscou mostrar que uma teologia, e um pensamento religioso, capazes de responder as novas dinâmicas da atual configuração global, precisam nascer nas fronteiras, pois lá é o local mais propício para se obter conhecimento.

Palavras-chave: Paul Tillich, Fronteira, Migração, Teologia, Ciências da Religião.

IN SEARCH OF THE BORDER AREA: THE FUTURE OF TILLICH'S THOUGHT IN FRONT OF (FUTURE) HUMANITY CONFIGURATION

\begin{abstract}
The present text evidence some moments of Paul Tillich's life, known as borders, the familiar relationship, the impact when change from camp to town and the experience like an immigrant, when moved out from his country. These events, affecting his childhood, youth, and during his entire existence helped him to formulate his thought. Highlighting
\end{abstract}

* Graduado em teologia e Pós-graduando em português: língua e literatura pela Universidade Metodista de São Paulo (UMESP). Participa dos Grupos de Pesquisa: Teologia no Plural, Paul Tillich de teologia e cultura (UMESP) e Literatura, Religião e Teologia LERTE (PUC/SP).E-mail: wanderson.s.campos@gmail.com. Link de acesso ao currículo Lattes: http://lattes.cnpq.br/1347905559102364. 
these points of Tillich's life, the paper shows that theology and religious thought are capable to respond news dynamics of the current global configuration, making new borders possible, for borders are the most propitious place to obtain knowledge.

Key-words: Paul Tillich; border; migration; theology; sciences of religion.

\section{Introdução}

$\mathrm{O}$ século XX foi um grande marco na construção do pensamento teológico. Dentre os vários nomes que contribuíram para isso, está o de Paul Johanes Tillich, visto como o maior teólogo desse século graças a sua contribuição, ao que é entendido por alguns como o segundo movimento teológico do século passado ${ }^{1}$, que ajudou a causar uma reviravolta antropológica na teologia (GIBELLINI, 2002). Falecido há mais de cinquenta anos, Paul Tillich é um dos poucos nomes no campo da teologia que construíram uma reflexão capaz de sobreviver a um século e permanecer ininterrupta, mesmo após sua morte. No entanto, foi dos anos 90 para cá, que o interesse pelo trabalho desse autor passou a aumentar. Tanto que diversas sociedades, associações e instituições teológicas ao redor do mundo têm se dedicado à exploração e aprofundamento de tópicos que Tillich estudou, e também à busca por compreender os pressupostos e limites de seu pensamento (CALVANI, 2016, p. 166).

No Brasil não é diferente, além da presença da Associação Paul Tillich, que periodicamente publica trabalhos ligados ao pensamento tillichiano, na revista Correlatio, o interesse por este teólogo vem crescendo, no campo protestante e católico e também, em círculos não-teológicos e seculares. "Em diferentes centros multiplicam-se trabalhos acadêmicos, artigos, formação de grupos de estudos e outras referências a Tillich que revelam a pertinência de sua produção para os dias de hoje" (RIBEIRO, 2003, p. 3). Segundo Calvani (2016), o trabalho de Tillich teve seu valor reconhecido por diversos estudiosos, que também eram destaque no século XX como Paul Ricoeur, Adorno, Horkheimer, Harvey Cox, Alexander Irwin, Ninian Smart, John Hick, Mark Taylor

Segundo Gibelini (2002), esse movimento era composto por: Bultmann, Fuchs e Ebeling e Karl Rahner. 
e até Gustavo Gutiérrez. Infelizmente, no "Brasil ainda não prestamos atenção às constantes referências a Tillich nos escritos acadêmicos de Rubem Alves, principalmente nos anos 1970 e 1980" (p. 166). Tudo isso indica que Tillich não é um teólogo que apenas agrada as pessoas, mas que presenteou o mundo da teologia e dos estudos de religião com um pensamento realmente marcante.

No entanto, Paul Tillich não é singular apenas em seus trabalhos. Eventos descritos em seus registros biográficos, como a relação com a família, a infância, mudança de cidade e adolescência, entre outros, ou seja, fases de sua existência, também têm muito que acrescentar à teologia e aos estudos da religião, pois entendemos que, da mesma maneira que os artefatos técnicos inventados pelo ser humano são extensões do corpo, a reflexão teológica que Tillich construiu é uma extensão daquilo que ele era, de suas experiências, dos elementos que foram fundamentais em sua vida, que o ajudaram a moldar sua personalidade e o acompanharam no restante de sua existência. A partir disso, nesse trabalho, destacaremos alguns pontos da vida de Paul Tillich, no objetivo de mostrar que, tanto a teologia como os estudos de religião, devem ser construídos nas fronteiras, pois para responder às constantes mudanças dessa era (pós)moderna, "a fronteira é o lugar mais propício para adquirir conhecimento" (TILLICH, 2003, p. 1). No entanto, é preciso dizer que apresentar traços biográficos desse teólogo não é nenhuma novidade, pois existem análises da vida e da obra de Tillich efetuadas por diferentes autores, que vêm acompanhadas pelos escritos autobiográficos do próprio teólogo ${ }^{2}$ que, na opinião de Ribeiro (2003), representam "conteúdos singulares, pois na medida em que Tillich sempre exerceu a tarefa de historiador não como um coletor de dados e de fatos, mas como um intérprete, os escritos autobiográficos dele tornam-se uma peculiar reflexão teológica" (p. 4). Dadas as diferentes possibilidades de sistematização para elaborar um quadro da

\footnotetext{
Quatro textos, dentre os escritos, podem ser destacados: i) 'What am I?' My search for Absolutes; ii) My Travel Diary: 1936 - Between two worlds; iii) On the boundary: an autobiographical sketch (que representa uma nova versão, revisada pelo autor, da primeira parte de The Interpretation of History (1936); e iv) "Autobiographical Reflections" (incluído em uma obra de vários autores sobre a teologia de Tillich, publicada originalmente em 1952). Além desses escritos, destaca-se também a introdução à obra The Protestant Era (1948), onde também são apresentados aspectos autobiográficos.
} 
vida desse teólogo, serão utilizados alguns registros destacados em $O n$ the Boundary, em que são apresentados momentos de sua vida e outros textos de autores brasileiros, que já apresentaram registros biográficos de Tillich.

\section{Uma vida construída na fronteira}

Tillich nasceu no século XIX, em 1886, em um pequeno povoado situado em Brandenburg, perto de Berlim, na Alemanha. Lá, durante toda sua infância, o ambiente familiar que o educou era bastante tradicional, dividido pela rígida e autoritária presença do pai, que era contrabalanceada pelo caráter maleável e democrático da mãe, coincidentemente chamada Johanna (CALVANI, 1995, p. 12). Até o início da Primeira Guerra Mundial, Tillich tinha uma vida bem estável, graças à relativa paz e ao florescimento da burguesia, mas essa estabilidade muda quando ele, junto com toda a família, tem que mudar para Berlim, graças ao trabalho do pai, que era um pastor luterano com bastante influência na hierarquia eclesiástica de sua igreja (RIBEIRO, 2003, p. 4). A relação familiar foi um importante fator que determinou a vida e o pensamento de Tillich, não apenas pelas influências que recebeu da mãe e do pai, mas especialmente por, desde pequeno, viver entre o temperamento de ambos, que eram bem diferentes. Essa é a primeira fronteira que esse incrível pensador vivenciou, o carinho por Johanna, sua mãe, que sempre teve seu amor e veneração, e a turbulenta e tensa relação com o pai, que se intensificou após 1900, com a mudança de cidade (CALVANI, 1995, p. 12).

A respeito dessa primeira fronteira, Tillich comenta que a união do pai e da mãe implantou nele a tensão entre a Alemanha oriental e a ocidental, pois no leste, região do pai, existia uma "inclinação imediata tingida com melancolia, uma acentuada consciência de culpa e pecado pessoal, um forte senso de autoridade e, tradições feudais ainda existentes", diferente do oeste, de onde veio a mãe, que era caracterizado pelo "entusiasmo de viver, concretude sensível, mobilidade, racionalidade e democracia”. Tendências que normalmente são transmitidas de maneira hereditária, mas que forneceram ao teólogo a substância que permitia 
que decisões fatídicas fossem tomadas no conjunto, pensamento e ação (TILLICH, 2003, p. 2-3, tradução nossa) 3 $^{3}$

Com a ida para Berlim, em 1900, Tillich, na época adolescente, se deparou com a segunda fronteira de sua vida, a existente entre cidade e país, que o teólogo percebe ao descobrir os atrativos da cidade grande, que contrastavam com a estreiteza da vida da aldeia (CALVANI, 1995, p. 12). Segundo Tillich, o pequeno vilarejo em que vivia era constituído por casas com "quintais, celeiros, e jardins anexados" e com apenas alguns minutos de caminhada, era possível ir de qualquer parte da cidade para os campos e, tanto na manhã, como no entardecer naquela região era possível ver o gado e as ovelhas sendo guiadas pela rua, o que caracterizava o local de sua infância como uma região rural. Essas, e outras características como as leis civis e as tradições particulares, que no caso faziam referência à idade média (TILLICH, 2003, p. 2; tradução nossa $)^{4}$ e, que eram parte daquela região, ganharam acentuação para Tillich quando ele se deparou com a estrutura da cidade, lugar que na lembrança do teólogo lhe pareceu algo meio místico (TILLICH, 2003, p. 2; tradução nossa) $)^{5}$. No entanto, apesar desse deslumbramento pela cidade, Tillich nunca perdeu sua consideração pela natureza, pois sua experiência no vilarejo, "despertou-lhe ainda na infância a consciência da ambiguidade: ao mesmo tempo em que apreciava a beleza e os ritmos da natureza, também atentava para seu caráter conflitivo e agressivo"

\footnotetext{
I have never doubted, at any rate, that the union of a father from the Mark and a mother from the Rhineland implanted in me the tension between eastern and western Germany: in the East a meditative bent tinged with melancholy, a heightened consciousness of duty and personal sin, a strong sense for authority, and feudal traditions are still alive; while the West is characterized by zest of living, sensuous concreteness, mobility, rationality, and democracy. It would not be possible, of course, to allocate these two groups of characters to my father and mother respectively. Yet it would seem that it was by way of them that these contradictory qualities were rooted in me-my life, inward and outward, to be enacted on their battleground. The significance of such congenital tendencies lies not in their determining the course of life, but in staking out the scope and supplying the substance within which the fateful decisions must be made in thought and action.

4 (...) many of the town houses have yards, barns, and gardens attached to them; just a few minutes walk will take one from any part of the town out into the fields; mornings and evenings cattle and sheep are herded through the streets. Nevertheless, these are true towns with their own civic rights and traditions going back to the Middle Ages.

5 (...) These were heightened by visits to Berlin, when the railway itself struck me as something half mythical; and thus there developed a yearning, overpowering at times, for the big city.
} 
(CALVANI, 1995, p.13). Foi também durante a infância, que Tillich teve experiências que lhe produziram admiração pelo sagrado, sua impressão do infinito e determinaram sua decisão em tornar-se teólogo, situações que produziram sensações que o acompanharam durante toda a vida e estavam presentes em seus trabalhos. Delas podemos destacar: o contato com a vida rural e a vida com a simplicidade (RIBEIRO, 2003, p. 5), as festas cristãs que modificavam o vilarejo, a liturgia e a vida sacramental experimentada na igreja (CALVANI, 1995, p. 14) e as visitas que fazia ao mar. A respeito desse último ponto, Tillich comenta que durante seu oitavo ano, passava semanas perto do mar e esses períodos são descritos como a experiência "da fronteira do infinito sobre o finito", junto com outro elemento que o jovem Tillich percebia no mar: "a dinâmica, a agressão sobre a terra em sua tranquila finitude, a extática qualidade dos ventos e das ondas" (TILLICH, 2003, p. 3, tradução nossa) ${ }^{6}$. Segundo o próprio teólogo, essas percepções que ele alimentou durante a vida, influenciaram a teoria da "Massa dinâmica" e sua doutrina do Absoluto ${ }^{7}$.

É de posse dessas experiências vivenciadas nos primeiros anos de vida, que a metodologia utilizada por Tillich na filosofia da religião tem como ponto de partida a noção do sagrado e Deus como ponto de chegada. Suas experiências de infância, especialmente o contato com a natureza e a simplicidade proporcionada pela vida rural, associadas a uma perspectiva de harmonia cósmica, fortaleceram no teólogo um sentimento de nostalgia "numinosa do infinito e a perspectiva da presença do divino no mundo". Disso, são derivados, "a mística, as implicações estéticas e sacramentais e os elementos lógicos e éticos da religião", o que mais tarde, sob a influência de Schleiemacher e Rudolf Otto, "redundou na participação de Tillich em movimentos de renovação

6 Most important, however, was the fact that from my eighth year onward annually I spent some weeks, later even months, by the seaside. The experience of the infinite bordering upon the finite (...) But there is also another element in the contemplation of the sea: the dynamic, the aggression upon the land in its tranquil finiteness, the ecstatic quality of gales and waves.

7 Thus the theory of the "Dynamic Mass" in my essay "Masse und Geist" ("The Mass and the Spirit") was conceived under the immediate impression of the agitated sea. Also for the doctrine of the Absolute as both ground and abyss of dynamic truth, and of the religious essence as the eruption of the eternal into finiteness, the sea supplied the imaginative element needed for these thoughts. 
litúrgica e em uma reavaliação do misticismo cristão e não-cristão" (RIBEIRO, 2003, p. 5).

Em seu relato biográfico, Tillich mostra que as fronteiras com que se deparou, determinaram sua vida. Apesar de termos apresentado apenas as fronteiras entre os diferentes temperamentos da mãe e do pai e cidade e país, esse, considerado o maior teólogo do século vinte, também experimentou fronteiras entre: classes sociais, realidade e imaginação, teoria e prática, heteronomia e autonomia, teologia e filosofia, igreja e sociedade, religião e cultura, luteranismo e socialismo, idealismo e marxismo. Talvez isso abra margem para pensarmos que as reflexões filosóficas e religiosas de Paul Tillich são híbridas, pois nasceram a partir da mistura de diferentes conceitos e experiências. Talvez seja por isso que Tillich tenha sido revisitado diversas vezes, por uma variedade de estudantes do Brasil, pois para uma sociedade como a brasileira, que teve como uma de suas características formadoras, o hibridismo ${ }^{8}$, nada melhor do que uma reflexão que dialoga com diferentes versões do pensamento.

No entanto, o momento em que vivemos é totalmente diferente do vivido por Tillich. A humanidade vem se transformando e a configuração fronteiriça do mundo não está ilesa disso e se a teologia de Tillich foi construída na fronteira, precisamos nos perguntar se haverá espaço para a teologia tillichiana e para as pesquisas vinculadas a ela, pois as fronteiras estão sendo repensadas e, também, refeitas e é isso que veremos agora.

\section{O futuro das fronteiras}

O fenômeno da globalização, entendido como a "mundialização" das relações econômicas, sociais e políticas, começou com a extensão das fronteiras comerciais no início do século XVI e avançou, dando saltos, ao longo de cinco séculos da expansão capitalista. Um dos re-

\footnotetext{
Segundo Gilberto Freyre, a sociedade brasileira formou-se, sob a colonização portuguesa como uma "sociedade agrária na estrutura, escravocrata na técnica de exploração econômica, híbrida de índio - e mais tarde de negro - na composição". Essa característica híbrida, era inevitável, pois na perspectiva do sociólogo, a colonização portuguesa tinha uma predisposição para o hibridismo, comportamento que explicava "seu passado étnico, ou antes, cultural, de povo indefinido entre Europa e África. Nem intransigente de uma nem de outra, mas das duas". (FREYRE, 2006, p. 66).
} 
sultados mais importantes desse processo, se não o mais, é o fantástico encurtamento do espaço e do tempo que a redução nos custos de transporte, juntamente com as tecnologias de informação e as telecomunicações, proporcionaram ao funcionamento das negociações comerciais em escala global. O "uso do fax, do telex, do correio eletrônico", da internet de modo geral, ou seja, de todos os recursos de comunicação on line, proporcionaram novas possibilidades à coordenação globalizada da atividade econômica (ARROYO; SANTOS, 1977, p. 58). No entanto, um resultado se desdobra dessa facilidade de negociação global, resultado que surgiu do enfraquecimento das fronteiras, pois graças ao contato das economias nacionais, que facilitou a mobilidade de bens, serviços e capitais, a mobilidade de pessoas também se tornou mais comum e facilitada, situação que foi evoluindo até resultar em uma das maiores questões mundiais do presente século, a chamada "crise migratória", que é entendida por algumas pessoas como a principal razão do afundamento da Europa e o sinal do colapso e da dissolução do modo de vida, conhecido, praticado e cultivado no continente europeu?

Contudo, apesar desse assunto estar sendo debatido com mais visibilidade atualmente, a migração em massa não é de forma alguma um fenômeno recente. Ela sempre esteve presente acompanhando os principais processos de desenvolvimento na história da humanidade e com a era moderna não foi diferente, pois desde sua gênese o fenômeno migratório esteve presente, especialmente porque o estilo de vida moderno produziu, e ainda produz, mulheres e homens "localmente inúteis" (pessoas que são excessivas ou não empregáveis, em razão do progresso econômico) e "localmente intoleráveis" (quem sofre rejeição em resposta a "agitações, conflitos e dissensões causados por transformações sociais/políticas e subsequentes em lutas de poder”) (BAUMAN, 2017, p. 9), realidade que, além de incentivar muitas pessoas a migrarem com

9 Para Zygmunt Bauman, essa questão mundial precisa ser vista em outra ótica, segundo o sociólogo, a "crise migratória" é um "codinome politicamente correto" que foi dado para uma das fases da "eterna batalha dos formadores de opinião pela conquista e subordinação das mentes e dos sentimentos humanos" (BAUMAN, 2016, p. 7) e nessa batalha, as mídias têm um papel fundamental, pois ao mesmo tempo em que transmitem notícias que tratam o fenômeno migratório como uma ameaça ao bem estar social, as crianças afogadas, os muros apressadamente erguidos, as cercas de arame farpado e os campos de concentração superlotados são cada vez menos manchete nos noticiários (BAUMAN, 2016, p. 8). 
suas próprias forças para outros espaços, também fortalece o tráfico humano, atividade que atualmente funciona tendo aproximadamente de 800 mil a 2 milhões de pessoas como vítimas que se dividem entre traficadas, vendidas, escravizadas, alugadas ou compradas, e entre elas $70 \%$ são mulheres e meninas, algumas com 6 ou 7 anos e até menos. Essas pessoas, "inúteis e intoleráveis", quando ultrapassam as diferentes barreiras, encontram acolhida nas partes desenvolvidas do planeta, locais onde "tanto imigrantes econômicos quanto refugiados" que procuram guarida são recebidos/as pelas empresas que adquirem "mão de obra barata e de atividades lucrativamente promissoras" (BAUMAN, 2017, p. 9). Só que para a massa da população, que é natural dessas regiões desenvolvidas e é assombrada pela "fragilidade existencial e pela precariedade de sua condição e de suas expectativas sociais", a presença dessas pessoas de fora é o sinal de uma maior competição pelo mercado de trabalho (BAUMAN, 2017, p. 10).

No entanto, é preciso dizer que é improvável que a migração em massa pare, pois diariamente aumenta o número de pessoas que procuram asilo, no desejo de fugir de regiões tomadas pela ausência de leis, por intermináveis guerras tribais e sectárias, assassinatos em massa "e de um banditismo permanente do tipo salve-se quem puder" (BAUMAN, 2017, p. 11), realidade que é sustentada por uma rede global com braços ligados a governos negligentes e ansiosos pelo aumento de seu PIB, policiais corruptos, organizações criminosas profissionais, famílias pobres, pessoas em estado de risco e com baixo nível de escolarização, sem esquecermos-nos de mencionar a atuação de um comércio global de armas livre de controle e que recebe "alimento" de "uma indústria armamentista ávida por lucros, e com o apoio tácito" (BAUMAN, 2017, p. 11-12).

O fluxo de refugiados impulsionados pelo regime de violência arbitrária a abandonar suas casas e propriedades consideradas preciosas, de pessoas buscando abrigo dos campos de matança, acrescentou-se ao fluxo constante dos chamados "migrantes econômicos", estimulados pelo desejo demasiadamente humano de sair do solo estéril para um lugar onde a grama é verde: de terras empobrecidas, sem perspectiva alguma, para lugares de sonho, ricos em oportunidades. (BAUMAN, 2017, p. 12) 
Esse quadro, além de confirmar que a migração em massa está longe de acabar, também desenha um esboço que nos permite considerar que o número de imigrantes, provavelmente, continuará crescendo até que seja estabelecido um equilíbrio nos níveis de bem-estar na humanidade $^{10}$, o que certamente levará muitas décadas para acontecer, mesmo sem levarmos em conta as viradas/guinadas sem previsão que o destino histórico dá. Só que enquanto essa realidade ainda não acontece, migrar continuará representando esperança, pois em um mundo que cada vez mais se torna turbulento, violento e inacessível, principalmente para as camadas mais pobres, sair de "casa" para morar em uma "terra estranha", mais do que um luxo ou capricho, é também uma tentativa desesperada de trocar a morte, clara e inevitável, pela oportunidade da vida, em um futuro duvidoso. "Refugiados da bestialidade das guerras, dos despotismos e da brutalidade de uma existência vazia e sem perspectivas têm batido à porta de outras pessoas desde o início dos tempos modernos" e, para quem está do outro lado ouvindo o "toc-toc", as pessoas que buscam refúgio, são estranhas e, por serem diferentes causam uma ansiedade fora do comum, pois são assustadoramente imprevisíveis, diferentemente "das pessoas com as quais interagimos todos os dias e das quais acreditamos saber o que esperar" (BAUMAN, 2017, p. 13-14). Como afirma Bauman, ao explicar o comportamento social europeu frente a enorme quantidade de imigrantes que só tende a aumentar,

Pelo que conhecemos, o influxo maciço de estranhos pode ser o responsável pela destruição das coisas que apreciávamos, e sua intenção é desfigurar ou abolir nosso modo de vida confortavelmente convencional. Essas pessoas com as quais estamos acostumados a coexistir em nossos

10 Em janeiro de 2017, foi divulgado um estudo da Oxfam, rede de ONGs destinada a estudar a desigualdade no mundo, que denunciou o quadro das desigualdades sociais a nível mundial. Segundo o estudo, que propõe a promoção de uma economia que beneficie todas as pessoas e não apenas algumas, mesmo com o comprometimento das lideranças mundiais em alcançar um objetivo global de reduzir a desigualdade, o fosso entre os ricos e o restante da sociedade aumentou. Tanto que uma das principais denúncias do documento é a de que oito homens brancos detém mais riqueza que a soma daquela destinada a 3,6 bilhões de pessoas - metade da humanidade e no Brasil, a concentração é ainda maior: seis bilionários tomam pra si mais do que metade da população. Para ver o estudo completo, basta acessar o link: https://www.oxfam.org.br/sites/default/files/ economia_para_99-relatorio_completo.pdf. 
bairros, nas ruas das cidades ou nos locais de trabalho, nós as dividimos em geral entre amigas ou inimigas, bem-vindas ou apenas toleradas. Mas, qualquer que seja a categoria em que as situemos, sabemos muito bem como nos comportar em relação a elas e como conduzir nossas interações. Sobre os estranhos, porém, sabemos muito pouco para sermos capazes de interpretar seus artifícios e compor nossas respostas adequadas - adivinhar quais possam ser suas intenções e o que farão em seguida. E a ignorância quanto a como proceder, como enfrentar uma situação que não produzimos nem controlamos, é uma importante causa de ansiedade e medo. (2017, p. 14).

Esse cenário apresenta um mundo globalizado que possui uma pseudo-ausência de fronteiras, mas se revela extremamente conservador e nacionalista, o que é antagônico ao mundo real, das dinâmicas sociais, que tem experimentado consequências absolutamente novas nos povos, na sociedade e em seus ecossistemas, graças a essa mobilidade humana que tem atingido dimensões impressionantes. A humanidade está sendo reconfigurada, basta olharmos para os

(...) processos culturais de desenraizamento, de deslocamento político, de crises econômicas, conflitos étnicos, culturais e religiosos, reposição das identidades, sincretismos, exportação de gostos, costumes, valores e mercadorias, embates e fusões, revolucionamento nas noções de espaço e tempo, mudança na percepção de si, do outro e do mundo. (ANPTECRE, 2017).

Tal (re)configuração se apresenta, de maneira especial como um grande desafio à teologia e aos estudos de religião, pois se o discurso teológico é "um jeito de falar sobre o corpo (...) um poema do corpo" (ALVES, 1982, p. 9) e a ciência da religião "é como um espelho em que nos vemos (...) uma ciência de nós mesmos" (ALVES, 2008, p. 13), nossa identidade, construída pelas nossas singularidades, é fundamental para a elaboração dos enunciados dessas duas vertentes do conhecimento que possuem uma relação tão íntima. No entanto, no atual mundo moderno até o processo de construção identitária é diferente. Atualmente as identidades estão disponíveis no ar, flutuando e se aglomerando ao redor do indivíduo, seja em resposta as escolhas que o[a] mesmo[a] faz, ou por estarem sendo "infladas e lançadas por quem está ao redor" (BAUMAN, 2005, p.19). Isso mostra a ideia, apresentada por Bauman 
(2005), que atualmente ter uma identidade coesa, firmada e construída solidamente seria, na realidade, um fardo capaz de limitar a possibilidade de escolher entre as diferentes opções que circulam ao redor. Pois identidade não é mais vinculada a algo concreto, como um espaço por exemplo. É possível sentir-se em casa, em qualquer lugar (BAUMAN, 2005, p.20) e a não pertença permite optar pela identidade desejada, frente a qualquer situação e em qualquer momento, o que provavelmente deve ser o que fazem, ou tentam, as tantas pessoas que integram o número de imigrantes ao redor do mundo.

No entanto, mesmo em meio a esse novo panorama perguntas religiosas do passado, que agora estão travestidas em meio aos símbolos secularizados e às novas formas de interação social, serão feitas. As teologias e os estudos da religião ainda precisarão responder sobre o sentido da vida e da morte e desenhar apontamentos para uma nova forma de alteridade nesse mundo de mobilidades constantes, pois agora, que tantos[as] estrangeiros[as] batem a nossa porta, precisamos saber quem é o[a] nosso[a] próximo[a] e, se acaso ainda somos tutores[as] de nossos[as] irmãos[ãs]. Isso tudo nos leva a pensar que poucos temas parecem tão desafiadores como as migrações e a mobilidade humana ${ }^{11}$, pois as religiões, além de participarem dessa realidade acompanhando seus "desenrolos", também estão sofrendo transformações, devido a esses mesmos processos de mobilidade e migração.

Quando voltamos para os registros que Tillich fez de sua vida, percebemos que para o teólogo, o migrar para outra "terra" sempre foi um tema importante para a teologia e, consequentemente para os estudos da religião. Notamos isso quando nos deparamos com a fronteira entre "casa e terra estranha", outra zona fronteiriça que experimentou em sua $v i^{12}{ }^{12}$, e que para ele não é meramente algo externo, que foi desenhado pela natureza ou pela história. A zona fronteiriça que é traçada entre

11 Aqui, é preciso levantar a informação de que, essa mobilidade não acontece apenas pelo fenômeno migratório ou do tráfico de pessoas. O turismo também tem movimentado uma crescente massa de pessoas ao redor do globo. Mulheres e homens que contribuem, significativamente para essa nova configuração da humanidade. "Segundo a Organização Mundial de Turismo (OMT), o turismo ao redor do mundo registrou em 2015 um recorde de 1,18 bilhão de viagens internacionais, 4,4\% a mais do que no ano anterior, $o$ que acrescentou 50 milhões de viajantes extras" (ANPTECRE, 2017).

12 Tillich experimentou essa fronteira quando expurgado da Alemanha, em 1933 após a chegada de Hitler ao poder, e vai para os Estados Unidos onde, um ano depois, começa a lecionar no Union Theological Seminary de Nova York e mais tarde, após sua aposentadoria, na Harvard University de Boston (GIBELLINI, 2002, p. 84). 
a terra natal e um ambiente estranho, é também um limite entre duas possibilidades de existência humana e que foram vividas por Abraão quando Deus o desafiou a abandonar sua terra natal e ir em busca de uma terra que lhe seria mostrada. Só que para isso, foi necessário que seus costumes familiares e culturais, como o culto religioso daquela região, e as pessoas daquele lugar, tudo, fosse deixado para buscar uma promessa que o próprio Abraão não compreendia (TILLICH, 2003, p. 30; tradução nossa) $)^{13}$. Isso fez Tilich perceber que o Deus exigente por obediência é o Deus de uma terra estranha que abençoa todos os povos e destrói, completamente, todos os nacionalismos religiosos, tanto de judeus, como de pagãos (TILLICH, 2003, p. 30) ${ }^{14}$. O que nos leva a pensar no mesmo víeis que esse teólogo ao propor que uma humanidade mais unida, além das fronteiras terrestres, represente e antecipe o que está implicado na crença do Reino de Deus, que consequentemente é negada pela negação da união da humanidade (TILLICH, 2003, p. 32; tradução nossa) ${ }^{15}$. Talvez essa constante movimentação em busca de uma vida melhor, ao mesmo tempo que é o resultado de uma política econômica mundial que prestigia algumas pessoas e desqualifica outras, também seja o anúncio de um reunião marcado pela união da humanidade e pela igualdade.

Esse cenário mundial se mostra propício para a teologia de Tillich, pois para elaborar novos discursos para essas pessoas que atravessam fronteiras territoriais e identitárias, é preciso uma teologia que foi construída também na zona fronteiriça e que apresente a ideia de que estar na linha da fronteira não representa apenas estar localizado[a] entre dois

13 The border of home and alien land is not merely the external boundary, drawn by nature or history, but is likewise the border of two inner forces, two possibilities of human existence. The classical word for it is the command to Abraham: "Go out from thy country-into a land that I shall show thee." Abraham must leave his native soil, the community of his family and cult, people and state, for the sake of a promise which he does not comprehend.

14 The God. who demands obedience from him is a God of an alien land, not attached to the native soil as are heathen gods, but a God of history, who means to bless all the races of the earth. This God, the God of the prophets and of Jesus, utterly destroys every religious nationalism: that of the Jews, which he combats constantly, and that of the pagans, which is repudiated in the command to Abraham.

15 This increasing realization of united mankind represents and anticipates, so to speak, the truth which is implied in the belief in a Kingdom of God, to which all nations and races belong. Consequently, the denial of the unity of mankind includes the denial of the Christian doctrine, namely that the Kingdom of God is at hand 
continentes, entre terra natal e estrangeira, mas também representa estar entre mundos, tempos, estar em tensão e movimento, pensar em diálogos, ao invés de monólogos (GIBELLINI, 2002, p. 85). Contudo, acreditamos que a teologia tillichiana também precisa atravessar outras fronteiras, diferentes das que o próprio Tillich experimentou, pois em um mundo em que as configurações têm um estado líquido e mudam com facilidade, o uso de uma teologia pura, sólida e sistemática pode ser prejudicial à tentativa de responder as perguntas que estão sendo repetidas e criadas, assim como as identidades estão sendo repetidas e criadas.

Tillich precisa ser levado às fronteiras que lhe permitam dialogar com reflexões mais atuais, mas que sejam de ouros campos do conhecimento. A teologia tillichiana precisa atravessar linhas e se tornar mais híbrida, se misturando com os pensamentos feministas, com as novas críticas sociológicas, com outros tipos de literatura e etc. A extensão do corpo de Paul Tillich que usamos em nossas reflexões, precisa ser pintada, ser usada para escrever trabalhos indecentes e desobedientes, para pensar em espaços míticos dentro de nós e de nossa vivência. Possivelmente a obra do maior teólogo do século XX ainda terá seu espaço garantido no futuro, porém, estamos sendo reconfigurados, especialmente na questão territorial e os espaços bem demarcados hoje, serão invadidos e tomados, pois o nosso futuro está além das fronteiras.

\section{Considerações finais}

Nossa tentativa no presente trabalho foi, a partir do destaque de alguns momentos da vida de Tillich, mostrar que as novas reflexões teológicas e religiosas precisam ser elaboradas na fronteira, mesmo espaço em que esse teólogo alemão viveu sua vida e teve experiências que fortaleceram seu pensamento. Acreditamos que além de apresentar essa ideia, mostramos que a nova configuração do cenário mundial abre espaço para que a obra de Tillich continue sendo revisitada e dando origens a novas reflexões. Contudo, consideramos necessário mostrar que o mundo não é o mesmo em que Paul Johannes Tillich viveu e por isso, seu pensamento precisa se misturar com reflexões que vêm sendo formuladas por um pensamento que é elaborado em novos espaços e não apenas nas realidades universitárias. É inegável a contribuição teológica de Tillich, e isso ganha ainda mais peso, quando sua vida se 
torna conhecida e ao lermos os escritos tillichianos, facilmente entendemos o motivo de essa obra ter superado os primeiros minutos da fama. Contudo, se Tillich não for carregado para atravessar as fronteiras que estão sendo mudadas, ele ficará para trás.

\section{Referências}

ALVES, R. O que é religião ?. 9. ed. São Paulo: Loyola, 2008.

. Variações sobre a vida e a morte: o feitiço erótico-herético da teologia. 3. ed. São Paulo: Paulinas, 1989.

ANPTECRE. Religião, migração e mobilidade humana. Texto de apresentação do VI Congresso da Associação Nacional de Pós-Graduação e Pesquisa em Teologia e Ciência da Religião. Disponível no link: <http://sites.pucgoias. edu.br/eventos/vianptecre/>. Acessado em 13 de janeiro de 2017.

ARROYO, M.; SANTOS, M. Globalização, regionalização: a proposta do Mercosul. In: Industria e globalização da economia. - Brasília: Sesi-DN, (Caderno Técnico 24). p. 55-63.

BAUMAN, Z. Identidade: entrevista a Benedetto Vecchi. Carlos Alberto Medeiros. Rio de Janeiro: Zahar, 2005.

Janeiro: Jorge Zahar, 2017.

. Estranhos à nossa porta. Carlos Alberto Medeiros. Rio de

CALVANI, C. E. A fronteira é o melhor lugar para adquirir conhecimento - circuntâncias históricas e pessoais da formação de Tillich. In: Estudos de Religião, v. 30, n. 3, p. 165-188, set.-dez. 2016.

. Paul Tillich - Aspectos biográficos, referenciais teóricos e desafios teológicos. In: Estudos de Religião, Ano X, n 10, p. 11-36, 1995.

FREYRE, G. Casa-grande \& senzala: formação da família brasileira sob o regime da economia patriarcal; apresentação de Fernando Henrique Cardozo. $-51^{\mathrm{a}}$ ed. ver. - São Paulo: Global, 2006.

GIBELlini, R. A teologia do século XX. João Paixão Netto. São Paulo: Loyola, 2002.

RIBEIRO, C. O. Teologia no Plural: Fragmentos biográficos de Paul Tillich. In: Revista Eletrônica Correlatio, v. 2, n. 3, p. 3-26, 2003.

TILLICH, P. The Interpretation of History. Arquivo eletrônico, disponível em: < http://media.sabda.org/alkitab-2/Religion-Online.org\%20Books/Tillich,\%20Paul\%20-\%20The\%20Interpretation\%20of\%20History.pdf $>$. Acessado em: 05 de janeiro de 2017. 